\title{
COMPETENCIAS DE LIDERAZGO EN EL PROCESO DE ENSEÑANZA APRENDIZAJE DE LOS ADMINISTRADORES DE EMPRESAS DE LA UNIVERSIDAD DE MANIZALES*
}

\author{
Laura Michel Santa Fajardo** \\ https://orcid.org/0000-0002-9270-0973 \\ Víctor Hernando Macías Ramírez ${ }^{* * *}$ \\ https://orcid.org/0000-0003-2904-5715 \\ Yomeida Inmaculada Bom-Camargo**** \\ (1) https://orcid.org/0000-0002-7345-2214 \\ Constanza Loreth Fajardo Calderón***** \\ https://orcid.org/0000-0001-6479-7379
}

RECIBIDO: Enero 2021 / ACEPTADO: Marzo 2021 / PUBLICADO: Mayo 2021

\begin{abstract}
Como citar: Santa Fajardo, Laura; Macías Hernández, Victor; Bom-Camargo, Inmaculada; Fajardo Calderón, Constanza. (2021). Competencias de liderazgo en el proceso de enseñanza aprendizaje de los administradores de empresas de la Universidad de Manizales. Telos: revista de Estudios Interdisciplinarios en Ciencias Sociales, 23 (2), Venezuela. (Pp.367-390).

DOI: www.doi.org/10.36390/telos232.10
\end{abstract}

\section{RESUMEN}

El artículo hace referencia a las competencias de la práctica empresarial, las básicas del liderazgo gerencial y las específicas de liderazgo; esenciales en el proceso formativo de los administradores de empresas de la Universidad de Manizales, teniendo en cuenta tanto las reflexiones y perspectivas del Proyecto Tuning América Latina periodo 2011-2013 (2021); como el perfil profesional y ocupacional propuesto por el programa y demás competencias que

\footnotetext{
* El artículo responde a las directrices desde el Grupo de Investigación Institucional 'Administración y Gerencia del Talento Humano' y su línea dirección y estrategia; y al Grupo de investigación en 'Mercadeo' en su línea de investigación Consumidor y entorno, ambos de la Universidad de Manizales. Igualmente, al Grupo de investigación en 'Derecho Tributario Comparado y Desarrollo Empresarial de la Universidad del Quindío -GEDUQ'

** Docente de planta del Programa de Administración de Empresas de la Universidad de Manizales. Candidata a doctor en Administración. Doctora in Business Administration- DBA. Magister en Administración- MBA, con énfasis en Gerencia de Negocios Internacionales. Especialista en Administración. Especialista en Educación Vocacional Docente. Especialista en Gestión de Proyectos de Desarrollo. Administradora de Empresas. Líder del Semillero de investigación 'Ética, Empresa y Sociedad' e Integrante del Grupo de Investigación 'Administración y Gerencia del Talento Humano' Universidad de Manizales. Correo electrónico: Isanta@umanizales.edu

*** Docente investigador de tiempo completo de la Universidad de Manizales. Magister en Administración. Especialista en estadistica. Administrador de Empresas. Tutor del Semillero de investigación 'Pensamiento empresarial', adscrito al Grupo de Investigación 'Administración y Gerencia del Talento Humano' de la Facultad de Ciencias Contables, Económicas y Administrativas -Universidad de Manizales. Correo electrónico: vmacias@umanizales.edu.co

**** Docente Asociada a tiempo completo de la Universidad de Manizales -Colombia. Docente Titular (Jubilada) Universidad Nacional Experimental Rafael María Baralt -Venezuela. Postdoctorado en Ciencias Humanas. Doctora en Ciencias Gerenciales. Magister en Gerencia Financiera. Economista. Integrante del Grupo de Investigación en Mercadeo de la Universidad de Manizales, con el proyecto "Industria 4.0 y su relación con los ODS", bajo la Línea de investigación Consumidor y entorno. Líder del Semillero de investigación: Producción y consumo responsable. Correo electrónico: yinmaculada@umanizales.edu.co

***** Docente de planta del programa de Contaduría Pública en la Universidad del Quindío. Doctora in Business Administration- DBA. Magister en Educación-Docencia. Magister en Ciencias Financieras y de Sistemas. Especialista en Ciencias Tributarias. Especialista en Control Fiscal para Entidades Públicas. Especialista en Pedagogía y Docencia. Contador Público. Investigador Asociado nombrado por Colciencias. Directora del Grupo de Investigación Institucional en 'Derecho Tributario Comparado y Desarrollo Empresarial de la Universidad del Quindío- GEDUQ' Correo electrónico: loreth@uniquindio.edu.co
} 
Competencias de liderazgo en el proceso de enseñanza aprendizaje de los administradores de empresas de la Universidad de Manizales

se requieren para dar solución a situaciones reales en las organizaciones. Para ello, se realizó una investigación con enfoque cuantitativo con un alcance exploratorio y correlacional, a través del método estadístico de Análisis de Componentes Principales, se aplicó la encuesta a los egresados (132) y estudiantes (81) como instrumento de recolección de datos. Se concluye que las competencias básicas de liderazgo gerencial son consideradas como cruciales en los procesos de formación de la población objeto de estudio, con las cuales están en capacidad de demostrar en su actuar: integridad, facilidad de comunicación, visión estratégica, enfoque hacia la obtención de resultados, toma de decisiones, habilidades de negociación, creación y desarrollo de equipos, perseverancia y administración del tiempo para afrontar los retos en su futuro profesional.

Palabras clave: competencias, competencias de liderazgo, enseñanza-aprendizaje, administradores de empresas, análisis de componentes principales.

\section{Leadership competencies in the teaching-learning process of business managers at the Universidad de Manizales}

\section{ABSTRACT}

The article refers to the competencies of business practice, the basic competencies of managerial leadership and the specific ones of leadership; essential in the formative process of business management at the Universidad de Manizales, taking into account the reflections and perspectives of the Tuning Latin America Project period 2011-2013 (2021); as well as the professional and occupational profile proposed by the program and other competencies that are required to provide solutions to real situations in organizations. For this purpose, a research with a quantitative approach with an exploratory and correlational scope was carried out, through the statistical method of Principal Component Analysis, the survey was applied to graduates (132) and students (81) as an instrument of data collection. It is concluded that the basic competencies of managerial leadership are considered crucial in the training processes of the population under study, with which they are able to demonstrate in their actions: integrity, ease of communication, strategic vision, focus on obtaining results, decision making, negotiation skills, team building and development, perseverance and time management to face the challenges in their professional future.

Key words: competencies, leadership competencies, teaching-learning, business managers, principal component analysis.

\section{Introducción}

El entorno empresarial y del trabajo se ha caracterizado por ser constantemente volátil, incierto, complejo y en muchos casos ambiguo para los colaboradores, lideres, gerentes y empresarios; lo que implica que deben asumir una serie de retos para ser capaces de negociar exitosamente con los stakeholders o grupos de interés en un entorno inestable, y así obtener resultados que conduzcan a la mejora de la calidad en la capacidad instalada e intangible. Además de reconocer y estar en capacidad de aprovechar como explica Winter (2020, p.909) "el poder de la ambigüedad y la incertidumbre, tomar decisiones sobre cuándo y cómo actuar, 
liderar a otros en un cambio complejo, y modelar las cualidades personales que sostienen tanto al líder como a los liderados".

En este sentido, para que la formación de los futuros líderes pueda prosperar en el medio, se requiere más que un desarrollo teórico de competencias, se exige una visión práctica de aquellas que puedan observarse, aplicarse, describirse y medirse en el entorno organizacional. Si no es así, la formación en liderazgo basada en competencias puede correr el riesgo de ser, simplemente, idealizada e incongruente; siendo insuficiente en la formación de los futuros administradores de empresas pues llega a ser un modelo fragmentado y coercitivo.

En cuanto a la formación por competencias, se vislumbra que no tiene un solo significado, sino que se han venido desarrollando de acuerdo con los objetos de estudio en las diferentes áreas de conocimiento como la psicología, la economía, la administración, la filosofía, los deportes, la educación, entre otros. El paradigma más utilizado en el ámbito universitario ha sido la formación laboral, con el fin de que a través del desarrollo de estas capacidades se aporte al bienestar de la sociedad y al desarrollo económico empresarial.

Para Bustamante et al. $(2015$, p. 24) la "enseñanza por competencias... en el contexto de la formación profesional, pone de manifiesto que los docentes aceptan la inminencia de la diversidad de sus estudiantes", sin embargo, reorientan la formación por competencias con la responsabilidad que asumen, pensando en el ideal desempeño de sus egresados en el campo laboral con el desarrollo de conocimientos, habilidades y destrezas. Por lo cual, el docente tiene una representación esencial en la formación por competencias, quien se considera, el actor principal y agente clave para lograr el cambio e innovación en la educación, "entiéndase actor principal, no en el sentido prescriptivo y comúnmente difundido como el dueño del conocimiento" (Díaz et al., 2010, p. 8)

Por consiguiente, los programas de formación en administración deben contemplar el desarrollo de habilidades, cualidades y atributos de liderazgo a la vanguardia de la demanda de la sociedad y que involucre los conocimientos tácitos y explícitos requeridos para prosperar en diferentes entornos. En este orden ideas, el programa de Administración de Empresas de la Universidad de Manizales cumpliendo con su función de lograr una formación integral centra su actuar hacía,

La comprensión y transformación de las organizaciones, como mecanismo para contribuir con el desarrollo social; por ello establece su accionar desde los valores, conocimientos, talento humano, innovación, comunicación, cultura, responsabilidad social, comprensión del contexto y pensamiento transformador crítico y creativo (Universidad de Manizales, 2017, p. 1)

Del mismo modo, tiene como eje fundamental al estudiante y al cuerpo docente en el proceso de enseñanza- aprendizaje para lograr que el futuro profesional tenga la capacidad de comprender el fenómeno organizacional y transformarlo, siendo imperativo desarrollar tanto "el conocimiento, que permita comprender y explicar los fenómenos sociales que ocurren en las organizaciones... como las diferentes competencias que lleven al individuo al logro de dicha comprensión" (Universidad de Manizales, 2017, p. 1).

De esta manera, las Instituciones de Educación Superior (IES), deben formar a los administradores no solo en teoría, sino que en la práctica sean capaces de ejercer su rol como emprendedores, empresarios, gerentes o líderes independientes tanto en el contexto local, 
Competencias de liderazgo en el proceso de enseñanza aprendizaje de los administradores de empresas de la Universidad de Manizales

regional, nacional o internacional; enfocándose en el liderazgo como competencia clave para mejorar e innovar en la gestión efectiva del proceso administrativo, dando respuesta a los intereses de los diferentes sectores tradicionales de la población (Grosso, 2013), como: el primer sector o sector público estatal, el segundo sector o sector productivo, y el tercer sector o denominado sector no lucrativo, integrado por entidades sin ánimo de lucro, organizaciones de la sociedad civil, organizaciones no gubernamentales, organizaciones de la economía solidaria y las empresas sociales "que se consideran la expresión de la sociedad civil" (Colombo et al., 2019, p. 662)

En el proceso de enseñanza-aprendizaje para los estudiantes de administración de empresas se debe involucrar no solo los pilares administrativos, sino aquellos derivados de los cambios en el papel de los gerentes; lo cual ha fortalecido a las universidades en el desarrollo de competencias necesarias para afrontar los cambios del entorno empresarial debido a la importancia de contribuir desde la actuación de los profesionales a la sostenibilidad económica, social y ambiental. Competencias que permiten al estudiante una comprensión y análisis crítico del contexto para la resolución de problemas prácticos y de la cotidianidad, y los que estén "en estrecha relación con las dinámicas organizacionales, de tal manera que se disminuya la brecha entre los conocimientos teóricos y la realidad empresarial, formando integralmente a los futuros administradores de empresas" (Santa et al., 2017, p. 118)

Sin embargo, en el proceso de formación por competencias no se puede generalizar, es necesario conocer cuáles son realmente las competencias que requiere el mercado. Por consiguiente, el presente artículo busca dar respuesta al siguiente interrogante ¿Cuáles son las Competencias de liderazgo que se han fortalecido en el proceso de enseñanzaaprendizaje del programa de administración de empresas de la Universidad de Manizales?

\section{Enfoque y diseño de la investigación}

Para el desarrollo de la investigación se siguió el procedimiento metodológico de Tacca (2021) en el que se define el diseño y enfoque de la investigación, los sujetos informantes, que para este caso se denominaron población y muestra, los instrumentos de recolección de la información y la validez de estos, y los análisis de los resultados.

La investigación se desarrolló bajo un enfoque mixto; desde lo cuantitativo con un alcance exploratorio y correlacional, "especialmente con técnicas de recolección de datos predeterminadas y altamente estructuradas" (Saunders et al., 2016, p. 166), para poder analizar adecuadamente el liderazgo y su desempeño organizacional. El método estadístico aplicado, fue el Análisis de Componentes Principales (ACP) de Karl Pearson (1901) (citado en Guevara, 2018), que permite "la obtención de información acerca de la interdependencia entre las variables examinadas" (Peña, 2014, p. 4 ), siendo el proceso más apropiado para estudios exploratorios (López y Fachelli, 2015) y así encontrar asociaciones entre las variables significativas. Con la aplicación del ACP, se pudo encontrar la cantidad mínima de variables que contienen el máximo de información implícita en los datos para los resultados.

En cuanto a la investigación cualitativa, se tuvo un alcance hermenéutico a los fines de interpretar y comprender los resultados desde la visión de los docentes las competencias específicas de liderazgo de los estudiantes y egresados del programa de administración de empresas de la Universidad de Manizales. 


\section{Población y muestra}

Para el estudio se calcularon dos muestras mediante muestreo aleatorio simple correspondiente a los egresados y estudiantes del programa de administración de empresas de la universidad de Manizales. De un total de 404 egresados se obtuvo una muestra de 132 y de un total de 130 estudiantes la muestra calculada fue de 81; ambos con un nivel de confianza del $95 \%$ y un margen de error del $7 \%$.

\section{Instrumentos de recolección de datos}

Se utilizó como instrumento de recolección de datos la encuesta, tanto para los egresados como estudiantes, de 20 preguntas cerradas en escala tipo Likert de 1 a 5 (Escobar et al., 2016), con el propósito de conocer el desempeño de tres tipos de competencias: en las prácticas empresariales, básicas en liderazgo y específicas en liderazgos. Se complemento la información obtenida con el intercambio verbal con los docentes participantes, se utilizó como instrumento de recolección de dato: la encuesta tanto para los egresados (132) y estudiantes (81).

Para la validez y confiabilidad de los instrumentos, se realizó una prueba piloto de la encuesta con una muestra de 22 egresados y estudiantes, en este caso el alfa real fue del $94 \%$ y el alfa estandarizado fue del $98 \%$, asimismo, fue enviada a pares externos, para que emitieran un juicio sobre el instrumento.

\section{Procedimiento}

Se decidió aplicar el instrumento con los egresados y estudiantes según la muestra calculada en el proceso de muestreo aleatorio simple (Scheaffer et al., 2013) mediante el programa estadístico R-Studio. Una vez obtenida la información y organizada la base de datos, esta se analizó con la técnica ACP que permite la estructuración del "conjunto de datos multivariado mediante la reducción del número de variables" (Díaz, 2012, p. 197), hasta identificar las variables con la mayor información sobre el problema analizado teniendo en cuenta que el modelo ACP no tiene variables dependientes.

El procedimiento implícito de esta técnica estadística conlleva al cálculo de correlaciones parciales de Pearson para analizar la colinealidad existente entre las variables que se introducirán al modelo, luego se realiza los Test de Bartlett y al de KMO (Káiser, Meyer y Olkin), para determinar la normalidad de los datos y el nivel de correlación entre las variables respectivamente (Guevara, 2018); y finalmente, se calcula los componentes principales a partir de su mayor varianza.

\section{Proceso de enseñanza- aprendizaje}

Si se quiere tener un resultado alentador en la formación por competencias, es esencial considerar los roles del profesor y del estudiante, dejando de lado el modelo tradicional; donde el sujeto activo es el docente y el sujeto pasivo es el estudiante, y "la actividad del profesor y de los alumnos gira alrededor del tema de estudio... y ellos deben concentrarse fielmente en la enseñanza temática del profesor" (Santa et al., 2017, p. 116); además en este modelo tradicional el desarrollo y evaluación del alumno:

No sigue un esquema sustentable pedagógica o psicológicamente, toda su acción gira alrededor del tema de estudio, sin tener en cuenta el desarrollo integral de su 
Competencias de liderazgo en el proceso de enseñanza aprendizaje de los administradores de empresas de la Universidad de Manizales

persona y sin llegar a tomar conciencia de su responsabilidad como primer gestor en la construcción de su formación (Castaño y Macías, 2005, p. 14)

En la función de mejorar los procesos académicos de enseñanza- aprendizaje por competencias, se debe incorporar el uso de las TIC (Tecnologías de la Información y Comunicaciones) y de las TAC (Tecnologías del Aprendizaje y el Conocimiento) en el ámbito universitario, debido a que promueve "la creación de nuevos entornos didácticos que trastocaron de manera directa a los actores del proceso de enseñanza-aprendizaje y al escenario mismo donde éste se desarrollaba" (Covarrubias, 2021, p. 152); impulsando las telecomunicaciones, como el m-learning, e-learning o aprendizaje electrónico móvil (Rodríguez y Coba, 2017)

En los nuevos procesos de enseñanza aprendizaje, surge el enfoque de Educación Basado en Competencias, el cual asume que la persona competente es capaz de dar respuesta a las diferentes problemáticas que enfrenta en su actuar profesional. Con esta estrategia, el docente orienta a los estudiantes a relacionarse con referentes científicos, culturales y actitudinales. Estas interacciones constantemente modifican y mejoran la formación generando "un alineamiento constructivo... que ordena objetivos, métodos y hasta sistemas de evaluación, donde el centro de atención está en la didáctica de co-construcción que rompe con la línea tradicional de profesor, contenido, método y evaluación" (Bustamante et al., 2015, p. 24)

\section{Competencias en la formación de los administradores de empresas}

En general las competencias se enfocan en demostrar las cualidades con las que cuenta un individuo (Alavi \& Leidner, 2001; Correa, 2007; Levy-Leboyer, 1997; Rodríguez, 2007) para aplicar sus conocimientos, destrezas, habilidades, actitudes y valores, entre otros, a la solución de situaciones reales; en otras palabras, una competencia es saber hacer en un contexto (Bogoya, 2000; Maldonado, 2001) y desempeñarse eficientemente en la vida laboral, ciudadana, social e intelectual (Cejas et al., 2019; Friesl et al., 2011)

Este concepto ha sido llevado al campo educativo con la finalidad de generar una formación transversal en las IES, en la medida que se rompe "con estructuras de cierta manera rígidas" (Sanabria-Rangel et al., 2019, p. 10)

Partiendo de las bases de las competencias genéricas del Proyecto Alfa Tuning de América Latina, en el que interviene Colombia, "Proyecto independiente, impulsado y coordinado por Universidades de distintos países, tanto latinoamericanos como europeos, cuya meta es identificar e intercambiar información y mejorar la colaboración entre las instituciones de educación superior para el desarrollo de la calidad, efectividad y transparencia" (Santa et al., 2016); se centra la atención en la aplicación de competencias genéricas, definiéndolas por Tobón (2015. pp. 71-73) como "aquellas competencias comunes a varias ocupaciones 0 profesiones... y específicas aquellas competencias propias de una determinada profesión".

El proyecto Tuning por medio de sus actividades plantea una serie de competencias genéricas para América Latina, siendo un listado de veinte y siete (27), y veinte (20) específicas de administración de empresas, fundamentadas de las ya existentes para Europa. La combinación de las competencias genéricas y específicas permite el aprendizaje integral 
del profesional (Santa et al., 2016), quien debe estar en capacidad de desarrollar las siguientes competencias como se observan en la tabla 1.

Tabla 1. Competencias genéricas y específicas Alfa Tuning- Innovación Educativa y Social

\begin{tabular}{|c|c|}
\hline ompetencias genéricas de & $\begin{array}{l}\text { Competencias específicas } \\
\text { Administración de empresas }\end{array}$ \\
\hline 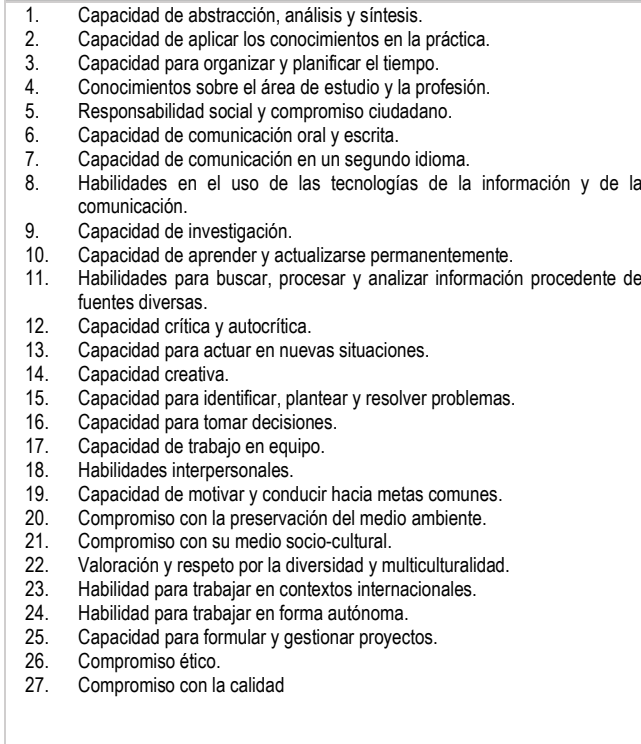 & 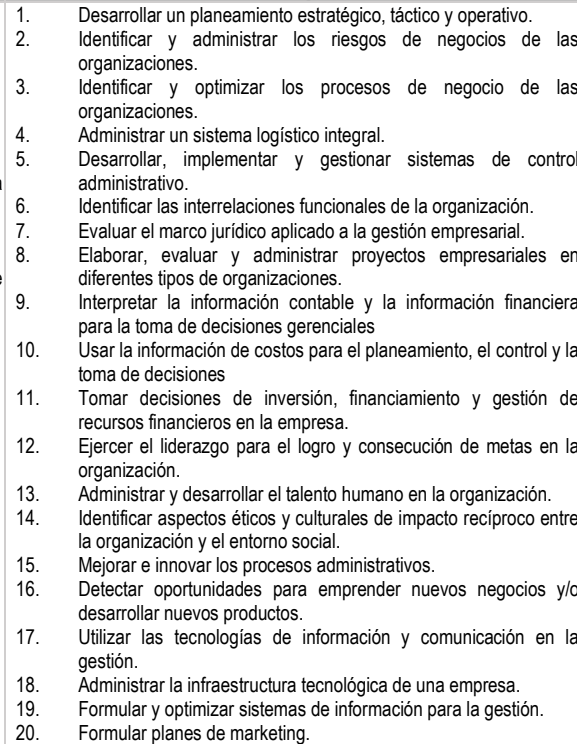 \\
\hline
\end{tabular}

Fuente: Adaptación de Alfa Tuning América Latina (2021)

De las competencias nombradas, para efectos de éste análisis, se fundamenta principalmente en la competencia especifica 'Ejercer el liderazgo para el logro y consecución de metas en la organización', donde el liderazgo es la clave para mejorar e innovar en la gestión efectiva del proceso administrativo, del negocio en los ámbitos financieros, técnicos y comerciales, y de los recursos tangibles e intangibles con los que se cuenta; potenciando al administrador, emprendedor o empresario a realizar las demás competencias específicas y combinándolas con las genéricas.

Por lo tanto, para lograr resultados de enseñanza- aprendizaje, la formación es crucial para el desarrollo de las competencias de liderazgo, y por ello, se requiere de una serie de estrategias metodológicas y tácticas de evaluación, entre ellas: "exposición dialogada, estudio de casos, juego de roles, desarrollo de proyectos, prácticas profesionales, simulación, dinámicas grupales, foros, debates y paneles, ensayos o trabajos escritos, presentaciones y exposiciones orales" (Esquetini, 2013, pp. 62-64). Lo anterior, proporciona un "conjunto de experiencias sistemáticas que ayudan a adquirir nuevos conocimientos relacionados con el liderazgo y oportunidades para practicar nuevas habilidades y capacidades" (Lacerenza et al., 2017, p. 1688) 
Competencias de liderazgo en el proceso de enseñanza aprendizaje de los administradores de empresas de la Universidad de Manizales

En consecuencia, la investigación se basa en el modelo de liderazgo por competencias, desde la teoría de la acción humana (Gorrochotegui, 2007) y en los fundamentos para la dirección de empresas, en la que se establece un acercamiento a los primeros criterios de competencias específicas para el liderazgo que determinan la calidad de una organización, como lo son según Gorrochotegui:

1. Eficacia: Como capacidad para lograr los objetivos propuestos, sin ella no se sobrevive. 2. Atractividad: Grado de satisfacción que experimentan los miembros de la organización por el trabajo que realizan y por el desarrollo que alcanzan. 3. Unidad: Grado de confianza e identificación de las personas con la misión de la organización. Confianza entre directivo y colaborador en cada nivel (Gorrochotegui, 2007, p. 92)

Por ende, el modelo de liderazgo por competencias permite el desarrollo formativo y evaluativo de los líderes, quienes comparten valores organizativos como: tener una mente visionaria, capacidad de gestión de los colaboradores, adaptabilidad a los cambios del entorno, orientación hacia los resultados y hacia los clientes, y comportamiento ético. Debido a que "una competencia puede incluir múltiples habilidades... desde la capacidad cognitiva, visión, eficacia interpersonal y eficacia directiva" (Wong, 2019, p. 600); generando que "los líderes desempeñen sus funciones de liderazgo con mayor eficacia" (Lord y Hall, 2005, p. 67). Modelo que es aplicado por las empresas "para desarrollar a sus líderes como agentes de confianza y así reducir los costes de agencia" (Muratbekova-Touron, 2009, p. 609). En este orden de ideas, se establecen unos niveles de competencias directivas (Cardona y García, 2009) que se centran en las personales internas, luego personales externas, hacia las interpersonales y las de negocio.

Este enfoque permite analizar, por un lado, cómo las competencias de negocio (estratégicas), aunque siguen estando encaminadas al logro de un valor económico para la empresa, ya integran en su finalidad el desarrollo social y ambiental del ecosistema que se logra por medio de la dirección de sus líderes quienes tienen la obligación de retribuir a la sociedad lo que ésta les ha brindado. Por otro lado, las competencias interpersonales para desarrollar las capacidades y la correcta funcionalidad de los colaboradores en sus diferentes niveles gerenciales. Lo anterior implica que las competencias son fundamentales para desarrollar la confianza (González et al., 2015) e identificarse con la misión de la empresa.

Por lo tanto, la competencia de liderazgo se refiere a "un conjunto de conocimientos, habilidades y capacidades necesarias para desempeñar eficazmente una función de dirección" (McCall et al., 1988) citado en Kragt y Day (2020, p. 2); y son "menos susceptibles de formación que los conocimientos, las habilidades y la capacidad, que son más sencillos y sugieren la adopción de iniciativas de desarrollo a largo plazo, basadas en la experiencia" (Kragt y Day, 2020, p. 3); y depende en gran medida de las actividades y los objetivos de una función puntual de dirección (Hollenbeck et al., 2006)

Simultáneamente, el enfoque amplía el horizonte para comprender mejor "cómo se operativizan los comportamientos de liderazgo para fomentar la identificación organizativa durante el cambio" (Aitken y von Treuer, 2020, p. 1), a fin de lograr que las iniciativas lideradas por un profesional con dichas competencias pueda responder flexiblemente y con éxito, en búsqueda de la legitimidad organizacional tanto interna como externa. El desarrollo de las 
competencias de liderazgo permite en el tiempo comprender la identidad del líder y el resultado de su carrera con el ascenso laboral o éxito empresarial, que normalmente se mide con el posicionamiento de los egresados de los programas de formación universitaria. Sin embargo, según Kragt y Guenter (2018, p. 406) "la identidad de los líderes sin experiencia se puede ver afectada por la formación en liderazgo en comparación con los líderes experimentados".

En este sentido, se analiza otra clasificación con diez (10) competencias asociadas explicitas en la tabla 2, producto de investigación sobre las Competencias del liderazgo Gerencial:

Tabla 2. Competencias del liderazgo gerencial

\begin{tabular}{|c|c|}
\hline $\begin{array}{ll}\text { Competencias } & \text { del } \\
\text { liderazgo Gerencial } & \\
\end{array}$ & Perspectiva \\
\hline Integridad y Confianza & $\begin{array}{l}\text { Cualidad de la persona recta y honesta, congruente entre su decir y su actuar, sin importar las } \\
\text { circunstancias y los riesgos. Condición de quien actúa éticamente, de acuerdo con las normas } \\
\text { sociales, se responsabiliza de sus actos, es directa y confiable en su trato con los demás. }\end{array}$ \\
\hline Hábil Estratega & $\begin{array}{l}\text { Capacidad de formular, implantar y evaluar las decisiones a través de las funciones que permitan a } \\
\text { una empresa lograr sus objetivos. Idéntica formas alternativas de alcanzar los objetivos escogidos y } \\
\text { determina luego qué acciones específicas se necesitan para ponerlos en la posición deseada. El } \\
\text { hábil estratega debe ser un líder creativo, innovador y con la iniciativa de promover nuevas } \\
\text { alternativas para visionar y alcanzar las metas organizacionales. }\end{array}$ \\
\hline Comunicación & $\begin{array}{l}\text { Construye contextos específicos a partir del lenguaje, que está intrínsicamente ligado a su postura } \\
\text { ante el mundo. Demuestra capacidad de realizar las lecturas adecuadas de las organizaciones con } \\
\text { la habilidad de escuchar atenta y activamente. }\end{array}$ \\
\hline Obtención de Resultados & $\begin{array}{l}\text { Aborda las diferentes situaciones de la vida con una constancia de voluntad que permita efectividad } \\
\text { en las acciones, es decir, sobrepasa la mera perseverancia que permite estar en la acción, para } \\
\text { obtener resultados sumándole el disfrute por hacer lo mejor posible en el menor tiempo, es decir, } \\
\text { lograr calidad en sus acciones. }\end{array}$ \\
\hline $\begin{array}{l}\text { Toma de Decisiones en la } \\
\text { Gerencia }\end{array}$ & $\begin{array}{l}\text { Es la capacidad con la cual el gerente, con la información disponible y el aprendizaje producto de la } \\
\text { experiencia, orienta la elección sistemática para analizar correctamente las situaciones y elegir una } \\
\text { o varias alternativas que lleven a una acción en pro de la solución de un problema. Dicha elección } \\
\text { se caracteriza por su calidad y oportunidad. }\end{array}$ \\
\hline Negociación & $\begin{array}{l}\text { Capacidad para lograr acuerdos favorables para la organización a la que pertenece, tanto interna } \\
\text { como externamente, mediante el diálogo y la puesta en juego de intereses comunes y opuestos. }\end{array}$ \\
\hline $\begin{array}{l}\text { Creación y Desarrollo de } \\
\text { Equipos }\end{array}$ & $\begin{array}{l}\text { Fomenta para la gestión general y la de los negocios en particular el desarrollo de equipos a partir } \\
\text { del convencimiento del valor estratégico que estos aportan. Comprende cabalmente el alcance de } \\
\text { sus acciones en relación con su equipo para una gestión exitosa de todos y cada uno de los } \\
\text { involucrados. Trabaja en equipo y sabe generar sinergia para que éste sea más que la suma de sus } \\
\text { partes. Sabe cómo hacer que un grupo se convierta en equipo eficiente de trabajo. Crea sinergias } \\
\text { de trabajo en el equipo. Guía y dirige un grupo y establece y mantiene el espíritu de grupo necesario } \\
\text { para alcanzar los objetivos de este }\end{array}$ \\
\hline Perseverancia & $\begin{array}{l}\text { Condición de mantenerse constante en la prosecución de lo comenzado, en una actitud o en una } \\
\text { opinión. Tenacidad, voluntad inquebrantable para superar las dificultades. Valor fundamental en la } \\
\text { vida para obtener un resultado concreto, mediante un esfuerzo continuado. }\end{array}$ \\
\hline Importancia en la Acción & $\begin{array}{l}\text { Capacidad para trabajar intensamente, enfrentando los desafíos con mucha energía. Resolución } \\
\text { para actuar con poca planificación, aprovechando las oportunidades que se presentan mejor que } \\
\text { otros. }\end{array}$ \\
\hline Administración del Tiempo & $\begin{array}{l}\text { Planea y organiza día de trabajo atendiendo ágil y oportunamente todas las actividades y } \\
\text { responsabilidades del diario quehacer; proyectado esto en la línea del tiempo a través de un } \\
\text { cronograma, cumpliendo con los tiempos previstos; siguiendo la planeación organizacional de } \\
\text { acuerdo a su misión y visión. }\end{array}$ \\
\hline
\end{tabular}

Fuente: Adaptado de Perilla y Martínez (2009)

Las competencias de liderazgo gerencial tienen alguna relación con las competencias específicas y genéricas, propuestas de los programas de administración, de igual forma con 
Competencias de liderazgo en el proceso de enseñanza aprendizaje de los administradores de empresas de la Universidad de Manizales

las que se pretende evaluar y que se espera se estén formando desde los procesos de enseñanza aprendizaje en las aulas de clase.

Todas estas observaciones se relacionan también con las IES, las cuales no deben tener restricciones a la hora de implementar estrategias de enseñanza- aprendizaje en los programas de administración de empresas, donde "los objetivos y planes de desarrollo suelen estar relacionados con la mejora de una habilidad o competencia específica, pero también pueden estar relacionados con la promoción profesional o incluso con la consecución de una aspiración vital más general" (Velasco et al., 2019, p. 2)

\section{Evaluación de las competencias del programa de administración de empresas de la Universidad de Manizales}

De acuerdo con el perfil de formación que presenta el programa de administración de empresas de la Universidad de Manizales, el futuro profesional se caracterizará por:

- Ser un ejecutivo idóneo, con competencias y capacidad para ejercer como empresario, gerente o consultor.

- Contar con capacidad de interpretar y explicar los fenómenos y complejidades de la dirección, de las estructuras de las organizaciones, del conocimiento, la cultura, la política, la economía y demás dinámicas del entorno.

- Ser líder y emprendedor con capacidad de innovación.

- Tener conciencia gremial, ambiental, ética y humana para tomar decisiones y actuar en coherencia con los principios sostenibles para las organizaciones y la sociedad en general (Universidad de Manizales, 2017)

En cuanto al perfil ocupacional, el profesional debe estar en capacidad de desempeñarse en organizaciones del sector público o privado, en empresas nacionales 0 internacionales, con o sin ánimo de lucro, dedicadas a la producción de bienes o servicios y podrá transitar en las diferentes áreas organizacionales, con suficiencia en:

- Ejercicio de posiciones directivas, de gerencia y consultoría en organizaciones públicas o privadas de carácter nacional e internacional.

- Ejecutar proyectos de análisis organizacional desde un enfoque multidisciplinar con miras al reconocimiento de las dimensiones, económicas, sociales y culturales propias de la Organización.

- Liderar una efectiva aplicación de gestión humana en la organización, que fortalezca tanto el desarrollo de las personas como el empresarial.

- Desarrollar proyectos tendientes a incursionar en los diferentes mercados.

- Formular y ejecutar políticas y estrategias de comercialización en los ámbitos nacional e internacional.

- Formular proyectos de investigación e intervención relacionados con las organizaciones.

- Liderar procesos de creación de empresa.

- Dirigir y gerenciar empresas nacionales con operaciones en mercados locales e internacionales.

- Interpreta y analiza los estados financieros para tomar decisiones de inversión, financiación y operación de las organizaciones.

- Formular y evaluar proyectos de inversión. 
- Realizar negociaciones de importación y exportación.

- Liderar procesos de negociación en diferentes escenarios, incluyendo los nacionales e internacionales (Universidad de Manizales, 2017)

Para responder a estos perfiles, el administrador de empresas debe formarse en competencias generales, específicas y gerenciales, lo que nos permitió evaluar las competencias del liderazgo que se han fortalecido en el proceso de enseñanza- aprendizaje del programa.

\section{Análisis por componentes principales (ACP)}

Con la aplicación del modelo ACP, se pudo definir los factores y categorías, que apuntaron a las variables que contienen el máximo puntaje y con las cuales se dio el análisis de los objetivos propuestos y se complementa con el uso de técnicas de la estadística descriptiva (Faraldo y Pateiro, 2012). En el proceso de recolección de datos, se determinaron 4 categorías de análisis o variables estudiadas como se observan en la tabla 3.

Tabla 3. Aspectos formativos, competencias en la práctica empresarial, competencias básicas de liderazgo gerencial y las competencias específicas de liderazgo en la formación de administradores de empresas

\begin{tabular}{|c|c|c|c|}
\hline Aspectos formativos & $\begin{array}{c}\text { Competencias en la práctica } \\
\text { empresarial }\end{array}$ & $\begin{array}{l}\text { Competencias básicas de } \\
\text { liderazgo gerencial }\end{array}$ & $\begin{array}{c}\text { Competencias específicas } \\
\text { de liderazgo }\end{array}$ \\
\hline $\begin{array}{l}\text { - Formación teórica. } \\
\text { - } \quad \text { Transforención práctica. } \\
\text { conocimiento teórico en } \\
\text { el contexto empresarial. } \\
\text { Capacidad de asumir } \\
\text { riesgos. } \\
\text { Incidencia de valores en } \\
\text { la toma de decisiones. } \\
\text { Desarrollo } \\
\text { competencias } \\
\text { gerenciales. }\end{array}$ & $\begin{array}{l}\text { - Trabaja en equipo en el } \\
\text { entorno laboral. } \\
\text { - Trabaja en forma autónoma. } \\
\text { Demuestra habilidades } \\
\text { interpersonales. } \\
\text { Motiva y conduce hacia metas } \\
\text { comunes. } \\
\text { Desarrolla, implementa y } \\
\text { gestiona sistemas de control } \\
\text { administrativo. } \\
\text { Se adapta en el entorno } \\
\text { laboral. } \\
\text { Actúa con responsabilidad } \\
\text { social y compromiso } \\
\text { ciudadano. } \\
\text { Tiene compromiso con la } \\
\text { preservación del medio } \\
\text { ambiente. } \\
\text { Demuestra capacidad creativa } \\
\text { e innovación en la acción } \\
\text { empresarial. } \\
\text { Ejerce el liderazgo para el } \\
\text { logro y consecución de metas } \\
\text { en la organización. }\end{array}$ & $\begin{array}{l}\text { - } \text { Integridad y confianza. } \\
\text { - } \quad \text { Comil estratega } \\
\text { - } \quad \text { Obtención de Resultados } \\
\text { - } \quad \text { Tema de Decisiones en la } \\
\text { - } \quad \text { Creación y desarrollo en } \\
\text { - } \quad \text { Peruipos } \\
\text { - Importancia en la acción } \\
\text { - } \\
\text { Administración del Tiempo } \\
\end{array}$ & 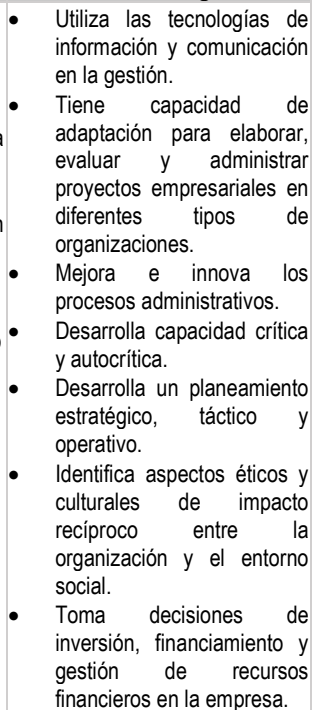 \\
\hline
\end{tabular}

Fuente: Elaboración propia

Las respuestas que brindaron los egresados y estudiantes fueron registradas y analizadas según la codificación de cada factor o categoría de análisis y sus sub-factores establecidos en a la tabla 3, para facilitar su tratamiento en el programa R- Studio, quedando de la siguiente manera: 
Competencias de liderazgo en el proceso de enseñanza aprendizaje de los administradores de empresas de la Universidad de Manizales

- AFORMATIVOS: Aspectos formativos.

- COMPETPRA: Competencias en la práctica empresarial.

- COMLIDER: Competencias básicas de liderazgo gerencial.

- ESPLIDER: Competencias específicas de liderazgo.

A continuación, se presentan el análisis en base al modelo ACP, comenzando con las matrices de correlación de Pearson para estudiantes (figura 1) y egresados en la (figura 2) respectivamente:

Figura 1. Matriz de correlaciones parciales de Pearson estudiantes cor (FAM)

AFORMATIVO COMPETPRA COMLIDER ESPLIDER

$\begin{array}{lllllll}\text { AFORMATIVO } & 1.0000000 & 0.9869010 & 0.9756653 & 0.9717892\end{array}$

$\begin{array}{lllllllll}\text { COMPETPRA } & 0.9869010 & 1.0000000 & 0.9850937 & 0.9785993\end{array}$

$\begin{array}{llllllll}\text { COMLIDER } & 0.9756653 & 0.9850937 & 1.0000000 & 0.9914001\end{array}$

$\begin{array}{lllllll}\text { ESPLIDER } & 0.9717892 & 0.9785993 & 0.9914001 & 1.0000000\end{array}$

Fuente: elaboración propia. Cálculos en R-Studio

La figura muestra que todas las variables tienen un nivel de correlación alto (superior a $0.90)$, lo cual justifica el análisis de componentes principales.

Figura 2. Matriz de correlaciones de Pearson Egresados cor (LIDER1)

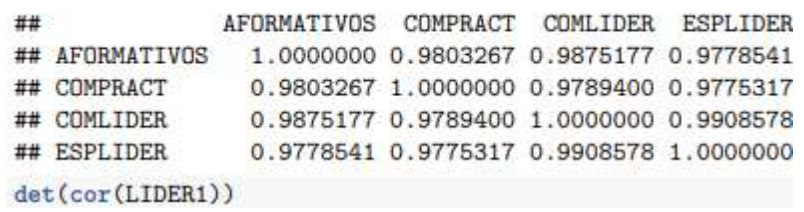

Fuente: elaboración propia. Cálculos en R-Studio

La matriz muestra que las correlaciones entre las variables son altas, por tal motivo, también se justifica el análisis por componentes, ya que un valor de correlación alto y positivo indica que los elementos miden la misma característica (Guevara, 2018)

Para completar el análisis se procede al Cálculo del test de Bartlett, prueba de que se utiliza para probar la hipótesis nula, que todas las varianzas de una población k son iguales, frente a la hipótesis alternativa de que al menos dos son diferentes. Si el P-valor es< a 0,05 entonces se acepta la hipótesis nula y se concluye que los datos provienen de una distribución normal (López y Fachelli, 2015). Los resultados de la prueba para los estudiantes y egresados se pueden observar en Figuras 3 y 4. 
Figura 3. Prueba de Bartlett para estudiantes

cortest. bartlett (cor (LIDER1), $\mathrm{n}=237$ )

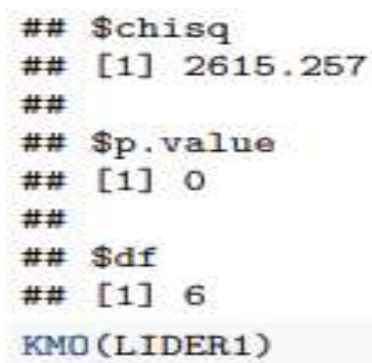

Fuente: elaboración propia. Cálculos en R-Studio

\section{Figura 4. Prueba de Bartlett para egresados}

cortest. bartlett (cor (FAM), $n=83$ )

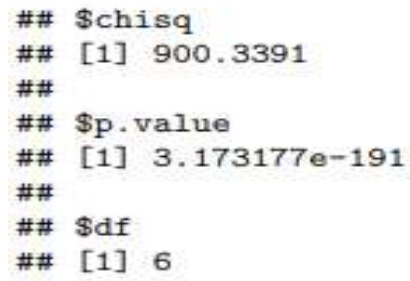

Fuente: elaboración propia. Cálculos en R-Studio

Los resultados de las figuras 3 y 4 , evidencia que el $p$-valor de estudiantes fue cero y el de egresados $3,173177 \times 10^{-191}$, por lo tanto, se puede concluir que hay homocedasticidad ${ }^{1}$ en los datos y estos provienen de una distribución normal.

En este sentido, se hace también, el test KMO (Káiser, Meyer y Olkin), con el fin de relacionar los coeficientes de correlación, observados entre las variables; cuanto más cerca de 1 tenga el valor obtenido del test KMO, implica que la relación entre las variables es alta, de esta manera la prueba evalúa la aplicabilidad del análisis factorial de las variables estudiadas cuando la correlación global y parcial se aproxime a uno (Sanchez, 2019)

En la figura 5 muestra que el coeficiente de correlación global en estudiantes es de 0,82 y la figura 6 muestra que el coeficiente de los egresados de 0,83 , igualmente los coeficientes de correlación de cada una de las categorías de análisis como: aspectos formativos (AFORMATIVO) en ambos casos el coeficiente supera el 0,80, competencias en la práctica empresarial (COMPETTRA), en el primer caso es 0,82 y en el segundo 0,91 , en

\footnotetext{
${ }^{1}$ Se entiende por homocedasticidad, según lo expuesto por Zapata (2020) al modelo estadístico predictivo que "ocurre si en todos los grupos de datos de una o más observaciones, la varianza del modelo respecto de las variables explicativas (o independientes) se mantiene constante"
} 
cuanto a las competencias básicas del liderazgo gerencial (COMLIDER), es más alta la correlación en estudiantes 0,79 que egresados 0,77 ,además es la correlación más baja de todas las categorías analizadas (correlación aceptable), finalmente las competencias específicas del liderazgo (ESPLIDER) fueron de 0,83 en los estudiantes y 0,82 en los egresados respectivamente. En general ambos grupos presentaron un nivel de correlación global muy semejante, que justifica la realización del análisis factorial.

Figura No. 5 Prueba de Test KMO estudiantes $\mathrm{KMO}$ (FAM)

\author{
Kaiser-Meyer-01kin factor adequacy \\ Call: $\mathrm{KMO}(r=\mathrm{FAM})$ \\ Overall $\mathrm{MSA}=0.82$ \\ MSA for each item =
}

AFORMATIVO COMPETPRA COMLIDER ESPLIDER
0.86
0.82
0.79
0.83

Fuente: elaboración propia. Cálculos en R-Studio

Figura No. 6 Prueba de Test KMO egresados KMO(LIDER1)

\author{
Kaiser-Meyer-0lkin factor adequacy \\ Call: $\mathrm{KMO}(\mathrm{r}=\mathrm{LIDER} 1)$ \\ Overall MSA $=0.83$ \\ MSA for each item $=$
}

\title{
AFORMATIVOS COMPRACT COMLIDER ESPLIDER
}
0.83
0.91
0.77
0.82

Fuente: elaboración propia. Cálculos en R-Studio

\section{Reducción de dimensiones y cálculo del número de componentes}

En esta fase se realizó el cálculo de las desviaciones estándar y las varianzas (eligen vectores) para determinar cuántos componentes principales explican el liderazgo en estudiantes y egresados del programa de administración de empresas, seleccionado aquellas variables que tengan varianzas mayores o iguales a 1. La salida de R-Studio muestra que la 
única varianza por encima del valor 1 corresponde al componente PC1 en ambos casos como se observan en las figuras 7 y 8 , destacando la importancia de los componentes y la proporción de varianza acumulada.

\section{Figura 7. Componentes principales para estudiantes}

\section{summary (acp)}

\section{\#\# Importance of components:}

$\begin{array}{lrrrr}\text { \#\# } & \text { PC1 } & \text { PC2 } & \text { PC3 } & \text { PC4 } \\ \text { \#\# Standard deviation } & 1.9861 & 0.18831 & 0.11248 & 0.08455 \\ \text { \#\# Proportion of Variance } & 0.9862 & 0.00887 & 0.00316 & 0.00179 \\ \text { \#\# Cumulative Proportion } & 0.9862 & 0.99505 & 0.99821 & 1.00000 \\ \text { des_stand<-acp [[1]] } & & & & \\ \text { des_stand } & & & & \\ \text { Fuente: elaboración propia. Cálculos en R-Studio } & & & \end{array}$

\section{Figura 8. Componentes principales para egresados}

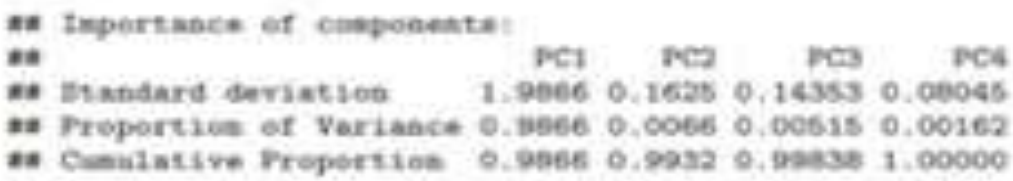

Fuente: elaboración propia. Cálculos en R-Studio

En la figura 7, se observa que sólo la componente uno, es la única que tiene una varianza superior a 1, lo cual se obtiene elevando la desviación estándar al cuadrado (estándar deviation); también es importante destacar que al reducir el número de categorías, se pierde información, aunque en proporciones muy pequeñas (Díaz, 2012). En este caso se puede observar que la proporción de varianza acumulada (cumulative proportion) en el primer componente es de 0,9862, en otras palabras, la componente uno contiene el 98,625 de la información. Igual que en los estudiantes, del instrumento aplicado a los egresados como se observa en la figura 8 , se obtiene una componente principal con una proporción acumulada de varianza de $98,66 \%$, lo que indica que el modelo tiene un alto poder explicativo con relación a las categorías de liderazgo que se analizarán a continuación.

Para conocer cuáles de las variables son las más representativas en cada una de las componentes principales de estudiantes y egresados, debemos seleccionar las que tengan los valores propios en términos absolutos más altos (Díaz, 2012), como lo muestra la figura 9 , donde en el lado izquierdo contiene los valores propios de la componente de estudiantes y el lado derecho los valores propios de la componente de egresados. 
Competencias de liderazgo en el proceso de enseñanza aprendizaje de los administradores de empresas de la Universidad de Manizales

Figura 9 Peso de cada categoría en las componentes de estudiantes y egresados

com_prin<-cbind (acp1, acp2,acp3, acp 4)
com_prin

acp1

AFORMATIVO 0.4986776

COMPETPRA 0.5007443

COMLIDER $\quad 0.5009460$

ESPLIDER $\quad 0.4996287$ con_prin<-cbind (acp1, acp2, acp3, acp4)

con_prin

$\begin{array}{lr} & \text { acp1 } \\ \text { AFORMATIVOS } & 0.4998961 \\ \text { COMPRACT } & 0.4987599 \\ \text { COMLIDER } & 0.5013729 \\ \text { ESPLIDER } & 0.4999676\end{array}$

Fuente: elaboración propia. Cálculos en R-Studio

En esta se observa que las categorías de más puntuación en estudiantes son COMPETPRA (competencias en la práctica empresarial) con 0,5007 y competencias básicas de liderazgo (COMLIDER) con 0,5009.

En la primera (COMPETPRA), es importante señalar que la práctica empresarial se constituye en un aspecto de gran relevancia para los estudiantes en la medida que les brinda una oportunidad de conocer el contexto organizacional, así como aplicar y desarrollar habilidades, competencias y actitudes necesarias para desempeñarse satisfactoriamente en el mundo laboral (Ibarrondo-Dávila, 2011), las competencias asociadas a esta categoría son: capacidad para trabajar en equipo, habilidad para trabajar en forma autónoma, habilidades interpersonales, capacidad de motivar y conducir hacia metas comunes; desarrollar, implementar y gestionar sistemas de control administrativo, capacidad de adaptación en el entorno laboral, responsabilidad social y compromiso ciudadano, compromiso con la preservación del medio ambiente, capacidad creativa e innovación en la acción empresarial, ejercer el liderazgo para el logro y consecución de metas en la organización (Bom; Bom y Bove, 2013).

En la segunda categoría (COMLIDER) competencias básicas de liderazgo gerencial, es muy importante para los estudiantes puesto que permiten en el tiempo comprender la identidad del líder y la proyección de un futuro exitoso en aspectos laborales 0 en emprendimientos personales. Las competencias asociadas a esta categoría están identificadas en: integridad y confianza, hábil estratega, comunicación, obtención de resultados, toma de decisiones en la gerencia, negociación, creación y desarrollo en equipos, perseverancia, importancia en la acción y la administración del tiempo.

En el caso de egresados, se observa que la categoría de más puntuación es COMLIDER (competencias básicas del liderazgo gerencial), dada la importancia de las competencias básicas como aspectos fundamentales para el desarrollo de cualquier actividad laboral, las competencias que se asocian a esta dimensión son: integridad y confianza, toma de decisiones, creación y desarrollo de equipos, obtención de resultados, importancia en la acción, comunicación, negociación, perseverancia y administración del tiempo (Perilla y Martínez, 2009) 


\section{Discusión y conclusión}

A lo largo de la investigación se pudo constatar que las competencias responden a cualidades, destrezas y habilidades, actitudes y valores con las que cuenta un individuo, y su capacidad de aportar al bienestar de la sociedad y al desarrollo económico empresarial a través de su formación, como lo afirman (Alavi y Leidner, 2001; Cejas et al., 2019; Correa, 2007; Friesl et al., 2011; Levy-Leboyer, 1997; Maldonado, 2001; Rodríguez, 2007). Competencias que se reflejan en los egresados y estudiantes del programa de administración, y responden además, al modelo de educación basado por competencias que se centra en la didáctica de co-construcción entre el cuerpo docente y estudiantil (Bustamante et al., 2015), para que ellos pueden dar solución a situaciones reales de su contexto y del entorno organizacional (Bogoya, 2000).

De esta manera, con respecto a los factores y subfactores producto del análisis del modelo ACP (Guevara, 2018), en la tabla 4 se refleja los aspectos formativos evaluados, y la comprensión sobre las competencias en la práctica empresarial, las básicas de liderazgo gerencial y las específicas de liderazgo que abordan tanto los egresados como los estudiantes del programa de administración de empresas de la Universidad de Manizales en su proceso de enseñanza - aprendizaje.

Tabla 4. Factores y subfactores de los aspectos formativos y competencias de liderazgo FACTORES O CATEGORIAS DE ESTUDIO

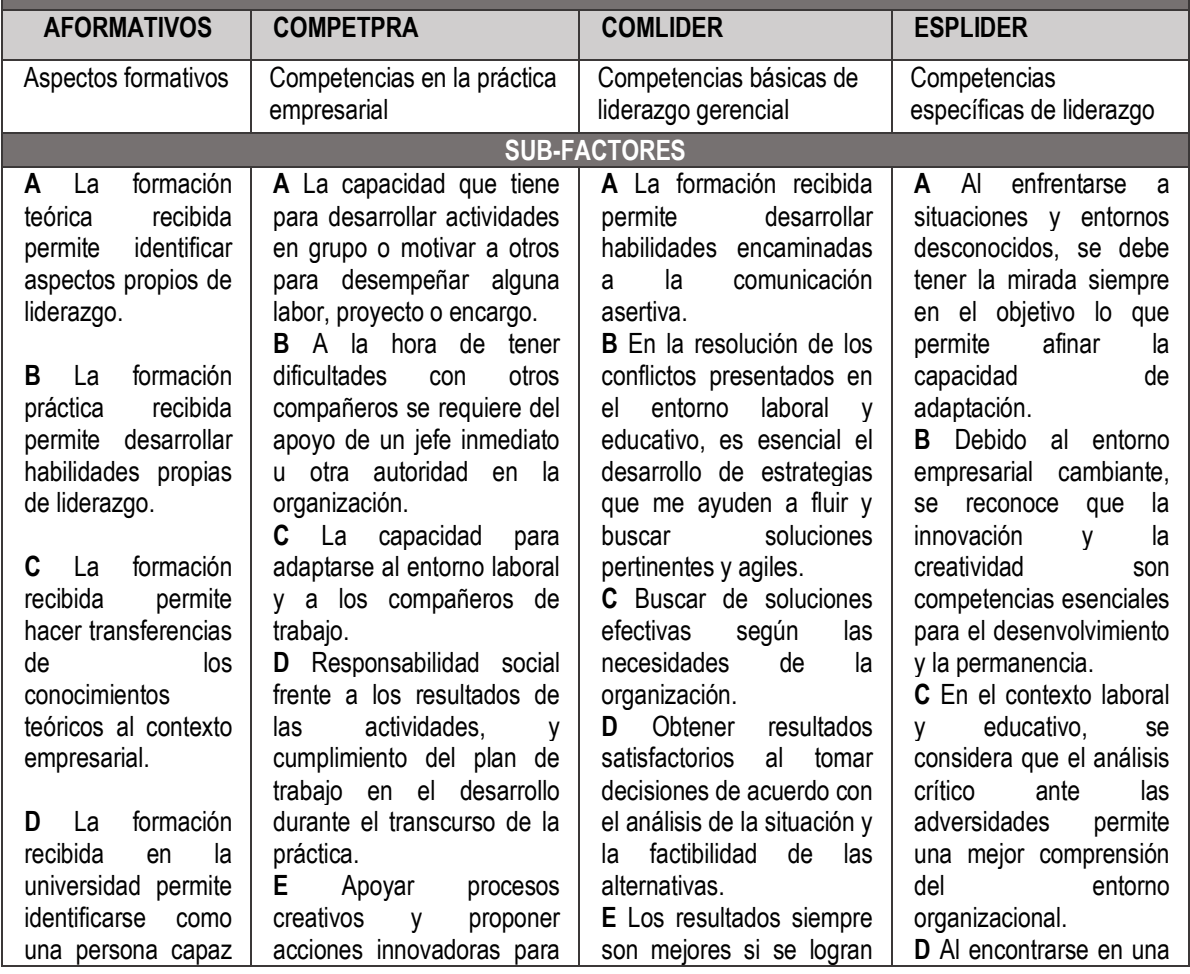


Competencias de liderazgo en el proceso de enseñanza aprendizaje de los administradores de empresas de la Universidad de Manizales

\begin{tabular}{|c|c|c|c|}
\hline 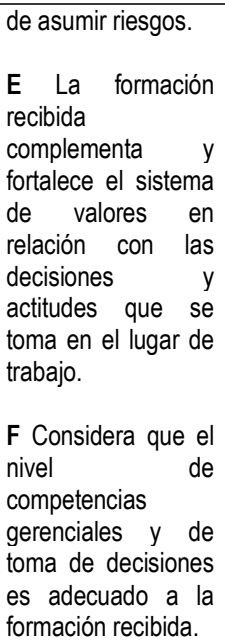 & $\begin{array}{l}\text { de mejoramiento de la } \\
\text { empresa. } \\
\text { F Manifestar su punto de } \\
\text { vista a los jefes y } \\
\text { compañeros sobre } \\
\text { situaciones en las cuales no } \\
\text { se está de acuerdo. } \\
\text { G Liderar y gestionar algún } \\
\text { proyecto, actividad o } \\
\text { evento. }\end{array}$ & $\begin{array}{l}\text { bajo la interacción y la } \\
\text { cooperación con otros. } \\
\text { F Al momento de } \\
\text { desarrollar cualquier } \\
\text { actividad en el entorno } \\
\text { laboral y educativo, el } \\
\text { tiempo juega un papel } \\
\text { importante y esencial que } \\
\text { necesita ser distribuido de } \\
\text { manera correcta. } \\
\text { G La capacidad de } \\
\text { negociación, interacción y } \\
\text { la generación de acuerdos } \\
\text { entre partes, son } \\
\text { esenciales para la } \\
\text { evolución y el crecimiento } \\
\text { empresarial. }\end{array}$ & $\begin{array}{l}\text { situación abrumadora en } \\
\text { el contexto formativo y } \\
\text { laboral, se debe guardar } \\
\text { la cordura, ser prudente } \\
\text { y no frustrase frente a la } \\
\text { adversidad para el } \\
\text { aprendizaje y la } \\
\text { adquisición } \\
\text { experiencia. } \\
\text { E Reconoce que en la } \\
\text { formación profesional } \\
\text { con respecto al } \\
\text { comportamiento ético } \\
\text { ayuda a entender y } \\
\text { actuar de manera } \\
\text { correcta en los } \\
\text { diferentes ámbitos } \\
\text { empresariales. rang }\end{array}$ \\
\hline
\end{tabular}

Fuente: Elaboración propia

En este sentido, se determina dentro del análisis de componentes principales, las competencias que fueron consideradas cruciales en los procesos de formación para egresados y estudiantes, agrupadas en la categoría COMLIDER, que se refieren a las básicas de liderazgo gerencial entre ellas: la integridad y la confianza, comunicación, ser hábil estratega, enfoque hacia los resultados, toma de decisiones, negociación, creación y desarrollo de equipos, perseverancia y administración del tiempo, soportadas por (Gorrochotegui, 2007; Perilla y Martínez, 2009).

No obstante, la habilidad de negociación según los expertos es fundamental, por lo que se requiere no solo alcanzarla con el desarrollo de prácticas empresariales sino a través de otras estrategias en el proceso de enseñanza-aprendizaje como los casos empresariales prácticos, simulaciones, estudios de roles, entre otras. De tal forma, que permita ir adquiriendo la experticia para su posterior vida laboral, planteamiento que concuerda con lo establecido por la Universidad de Manizales (2017). Además, esta competencia, es considerada como una habilidad blanda, con la que se puede mejorar los procesos de socialización, disminuir la agresión y facilitar la interacción con otros, buscando establecer un acuerdo mutuo y disminuir posibles consecuencias negativas producto de divergencias ante un mismo evento o situación (Guerra-Báez, 2019).

Mediante la investigación se pudo identificar también, que los egresados, estudiantes y docentes expertos, reconocen que la práctica empresarial permite la formación de líderes capaces de entender las problemáticas del entorno, en consonancia con las solicitudes de los empresarios locales; siendo el principal laboratorio para el desarrollo de competencias comprendidas en la categoría de COMPETPRA, en la que se tuvo en cuenta las genéricas y específicas del proyecto Alfa Tuning América Latina (2021) de la innovación educativa y social, impulsado y coordinado por universidades latinoamericanas y europeas (Santa et al., 2016) enfocado en identificar e intercambiar información y mejorar la colaboración entre las instituciones (Esquetini et al., 2013). 
Por lo tanto, las competencias en la práctica empresarial se refieren a las habilidades para trabajar en equipo en el entorno laboral, trabajar de forma autónoma, demostrar habilidades interpersonales, motivar y conducir hacia metas comunes, desarrollar, implementar y gestionar sistemas de control administrativo, adaptarse en el entorno laboral, actuar con responsabilidad social y compromiso ciudadano, tener compromiso con la preservación del medio ambiente, demostrar capacidad creativa e innovación en la acción empresarial, y ejercer el liderazgo para el logro y consecución de metas en la organización.

Simultáneamente, en esta categoría se destacan las competencias de trabajo en equipo en el entorno laboral y la de demostrar capacidad creativa e innovación en la acción empresarial, puesto que se consideran clave para el buen desempeño laboral y el crecimiento organizacional. En este orden de ideas, el futuro profesional debe ser sociable, inquisitivo, observador, creativo, inventivo, líder, motivador, persistente y con determinación; a fin de incentivar la conformación de equipos de alto rendimiento y multidisciplinarios para aprovechar oportunidades y transformarlas en proyectos, asumir riesgos, tolerar la frustración, y ser flexible para adaptarse al entorno.

Por lo anterior, son los docentes como actor principal para lograr el cambio e innovación en la educación (Díaz et al., 2010), quienes deben fomentar en los procesos de enseñanza-aprendizaje, dichas habilidades y destrezas para el trabajo en equipo y el aprendizaje por descubrimiento; por lo que "se recomienda emplear ciertos términos y procedimientos de la metodología científica indistintamente de la naturaleza de los cursos" (Tacca 2021, p. 408) para que lo egresados y estudiantes demuestren su capacidad de integración, comunicación, trabajo autónomo y relaciones interpersonales (Ibarrondo-Dávila, 2011)

En conclusión, las IES deben asumir un reto fundamental en la construcción de sociedad y economía del conocimiento, por lo que están llamadas a prestar especial interés en el entrenamiento de habilidades blandas y gerenciales como parte esencial de la formación integral (Guerra-Báez, 2019), del administrador de empresas, que les ayude a gestionar los cambios del entorno y adaptarse a condiciones de estrés u otras situaciones derivadas de la actividad empresarial.

En corolario, es posible determinar que en el proceso formativo de la Universidad de Manizales se les posibilita a los estudiantes reconocer aspectos de liderazgo gerencial en el mercado laboral, lo cual les permite identificar y potenciar sus competencias en el proceso de transferencia del conocimiento a la labor. Este hallazgo sirve de base para afirmar que los egresados del programa de administración de empresas asumen la realidad laboral como un todo y enfrentan las adversidades de manera plena, acción que fortalece y hace reconocida su capacidad de adaptación. Se deduce, además, que realmente los resultados son claros y admiten también que los valores éticos, son importantes para los profesionales y que en su proceso formativo se potencian de manera significativa, evento que se refleja directamente el en su accionar diario.

Por lo tanto se infiere, que en función de las relaciones existentes entre liderazgo, procesos grupales e innovación, los docentes deben intervenir al fomentar ciertas habilidades en los estudiantes para estimularlos, y para ello se requiere no sólo conocimientos técnicos y profesionales propios del área de actuación del equipo, sino también habilidades de desarrollo de la creatividad que les permitan movilizar su potencial en realizaciones prácticas como 
Competencias de liderazgo en el proceso de enseñanza aprendizaje de los administradores de empresas de la Universidad de Manizales

proyectos (González-Romá, 2009), diagnósticos e investigaciones en el contexto real de las empresas, que contribuya al cumplimiento de los objetivos de desarrollo sostenible, con el fin de promover sociedades pacíficas e inclusivas que faciliten crear instituciones eficaces, responsables e inclusivas a todos los niveles (Programa de las Naciones Unidas- PUND, 2020)

\section{Referencias Bibliográficas}

Aitken, Kim y von Treuer, Kathryn. (2020). Leadership behaviours that foster organisational identification during change. Journal of Organizational Change Management. Vol. ahead-of-print No. ahead-of-print. United Kingdom. https://doi.org/10.1108/JOCM-012020-0029

Alavi, Maryam y Leidner, Dorothy. (2001). Review: Knowledge Management and Knowledge Management Systems: Conceptual Foundations and Research Issues. Management Information Systems Research Center, University of Minnesota. 25 (1), United States. (pp. 107-136) https://moodle.ufsc.br/pluginfile.php/950622/mod_resource/content/1/MISQ $2001 \mathrm{Vol} 25$ No. 1 page 107 Alavi Leidner.pdf

Alfa Tuning América Latina. (2021). Competencias específicas de administración de empresas. 2011-2013 Innovación Educativa y Social. Europe Aid Co-operation Office. España. Extraído http://www.tuningal.org/index.php?option=com content\&view=article\&id $=165 \& /$ temid $=17$ $\underline{4}$

Bogoya, Daniel. (2000). Competencias y proyecto pedagógico. Universidad Nacional de Colombia. Colombia

Bom, Yosmary; Bom, Yomeida y Bove, María. (2013). Responsabilidad social y productividad laboral. Gestión y Gerencia. 7 (3). Venezuela. (pp. 52-66). https://dialnet.unirioja.es/servlet/articulo?codigo $=5301135$

Bustamante, Miguel; Oyarzún, Claudio; Grandón, Maderline y Abarza, Caroline. (2015). Fundamentos de la enseñanza por competencias a nivel de postgrado en dos universidades públicas Chilenas. Formacion Universitaria, 8 (6), Chile. (pp. 23-30) https://scielo.conicyt.cl/pdf/formuniv/v8n6/art04.pdf

Cardona, Pablo y García, Pilar. (2009). Como desarrollar las competencias de liderazgo. Eunsa. Ediciones Universidad De Navarra, S.A. España.

Castaño, German; Macías, Víctor. (2005). Una mirada a las competencias, como referente de formación integral para administradores de empresas de la Universidad Nacional Sede Manizales. Revista EAN. 54, Colombia. (pp. 5-26) https://www.redalyc.org/pdf/206/20605401.pdf

Cejas, Magda; Rueda, María; Cayo, Luis y Villa, Luisa. (2019). Formación por competencias: Reto de la educación superior. Revista de Ciencias Sociales. 25 (1), Venezuela. (pp. 94-101). https://dialnet.unirioja.es/servlet/articulo?codigo $=7025815$

Colombo, Laura; Pansera, Mario y Owen, Richard. (2019). The discourse of eco-innovation in the European Union: An analysis of the Eco-Innovation Action Plan and Horizon 2020. Journal of Cleaner Production. 214, United Kingdom. (pp. 653-665). https://doi.org/10.1016/i.jclepro.2018.12.150

Correa, Jorge. (2007). Orígenes y desarrollo conceptual de la categoría de competencia en el 
contexto educativo. Serie Documentos Investigación de La Editorial Universidad Del Rosario, Colombia (pp. 1-33) https://repository.urosario.edu.co/bitstream/handle/10336/3768/origenes y desarrollo 25 enero 8-2008.pdf?sequence=4\&isAllowed=y

Covarrubias, Liliana. (2021). Educación a distancia: transformación de los aprendizajes. Telos

Revista de Estudios Interdisciplinarios En Ciencias Sociales. 23 (1), Venezuela. (pp. 150-160) https://doi.org/10.36390/telos231.12

Díaz, Claudio; Martínez, Patricia; Roa G, Iris y Sanhueza, María. (2010). Los docentes en la sociedad actual: sus creencias y cogniciones pedagógicas respecto al proceso didáctico. Polis Revista Latinoamericana. 9 (25), Chile. (pp. 1-15) https://journals.openedition.org/polis/625

Díaz, Luis. (2012). Estadistica Multivariada: Inferencia y Métodos. Universidad Nacional de Colombia. Colombia

Escobar, Robin; Yepes, Adriana; Bedoya, José. (2016). Diagnóstico de los conocimientos y actitud hacia la matemática en instituciones públicas de educación básica y media de la ciudad de Pereira. Universidad Tecnológica de Pereira / Distribuido por Lemoine Editores (ed.) Colombia.

Esquetini, Cesar (Editor). (2013). Educación Superior en América Latina: reflexiones y perspectivas en Administración. Publicaciones de la Universidad de Deusto. http://tuningacademy.org/wp-content/uploads/2014/02/RefAdministration_LA_SP.pdf

Faraldo, Pedro y Pateiro, Beatriz. (2012). Estadística y metodología de la investigación. Curso 2012-2013 Grado en enfermeria. Tema 1. estadistica descriptiva. Departamento de Estadística e Investigación Operativa. Universidad Santiago de Compostela. España http://eio.usc.es/eipc1/BASE/BASEMASTER/FORMULARIOS-PHP-

DPTO/MATERIALES/Mat_G2021103105_Presentaci\%C3\%B3n_Tema1.pdf

Friesl, Martín; Sackmann, Sonja y Kremser, Sebastian. (2011). Knowledge sharing in new organizational entities: The impact of hierarchy, organizational context, micropolitics and suspicion. Cross Cultural Management: An International Journal. 18 (1), United Kingdom. (pp. 71-86) https://www.emerald.com/insight/content/doi/10.1108/13527601111104304/full/html

González, Erika; Carrión, Andrés y Palacios, Daniel. (2015). El liderazgo por competencias y el EFQM. Investigación Administrativa. 44 (116), México. (pp. 1-25) https://www.ipn.mx/assets/files/investigacion-administrativa/docs/revistas/116/art1.pdf

González-Romá, Vicente. (2009). La innovación en los equipos de trabajo. Papeles Del Psicólogo, Vol $29 \quad$ (1), España. (pp. 32-40) https://www.redalyc.org/pdf/778/77829105.pdf

Gorrochotegui, Alfredo. (2007). Un modelo para la enseñanza de las competencias de liderazgo. Educ.Educ Universidad de La Sabana, Facultad de Educación. 10 (2), Colombia (pp. 87-102). http://www.scielo.org.co/pdf/eded/v10n2/v10n2a07.pdf

Grosso, Carlos. (2013). La economía social desde tres perspectivas: tercer sector, organizaciones no gubernamentales y entidades sin ánimo de lucro. Revista Tendencias \& Retos, Universidad de Costa Rica. 18 (1), Costa Rica. (pp. 143-158) https://dialnet.unirioja.es/servlet/articulo?codigo $=4929405$

Guerra-Báez, Sandra. (2019). Una revisión panorámica al entrenamiento de las habilidades 
blandas en estudiantes universitarios. Psicologia Escolar Educacional. 23, Brasil. (pp. 1-11) http://www.scielo.br/pdf/pee/v23/2175-3539-pee-23-e186464.pdf

Guevara, Meyer. (2018). Análisis de Componentes Principales (PCA). RPubs. Escuela de Ciencias Biológicas, UNA-Costa Rica. http://rstudio-pubsstatic.s3.amazonaws.com/392044_0b4367f9ebf94853a1b80740dd2aedcb.html

Hollenbeck, George; McCall, Morgan y Silzer, Robert. (2006). Leadership competency models.

The Leadership Quarterly. 17 (4), United States. (pp. 398-413). http://intra.pare.ee/files/Hollenbeck\%20et\%20al\%202006_KMte\%20v\%C3\%A4\%C3\%A4 rtus_0.pdf

Ibarrondo-Dávila, María. (2011). Práctica empresarial y desarrollo de habilidades en el aprendizaje. EDUCADE - Revista de Educación En Contabilidad Finanzas y Administración de Empresas, 2, España. (pp. 35-50) www.doi.org/10.12795/EDUCADE.2011.i02.03

Kragt, Darja y Day, David. (2020). Predicting Leadership Competency Development and Promotion Among High-Potential Executives: The Role of Leader Identity. Frontiers in
Psychology.
11,
Belgium.
(pp.
$1-16)$

https://www.ncbi.nlm.nih.gov/pmc/articles/PMC7419574/

Kragt, Darja y Guenter, Hannes. (2018). Why and when leadership training predicts effectiveness: The role of leader identity and leadership experience. Leadership \& Organization Development Journal. 39 (3), United Kingdom. (pp. 406418) https://doi.org/10.1108/LODJ-11-2016-0298 https://core.ac.uk/download/pdf/231484049.pdf

Lacerenza, Cristina; Reyes, Denise; Marlow, Shannon; Joseph, Dana y Salas, Eduardo. (2017). Leadership training design, delivery, and implementation: a meta-analysis. Journal of Applied Psychology. 102 (12), United States. (pp. 1686-1718) DOI: $10.1037 /$ apl0000241

https://www.researchgate.net/publication/318737359_Leadership_Training_Design_Deli very_and_Implementation_A_Meta-Analysis

Levy-Leboyer, Claude. (1997). Gestión de las competencias. Gestión 2000. $1^{\text {a }}$ Edición. España.

López, Pedro y Fachelli, Sandra. (2015). Metodología de la inverstigación social cuantitativa. Universitat Autònoma de Barcelona (ed.). España https://ddd.uab.cat/pub/libres/2015/129382/metinvsoccuan_presentacioa2015.pdf

Lord, Robert y Hall, Rosalie. (2005). Identity, deep structure and the development of leadership skill. The Leadership Quarterly. 16 (4), United State. (pp. 591-615) https://www.sciencedirect.com/science/article/pii/S1048984305000652

Macias, Victor y Ramírez, Duván. (2011). Sucesión en empresas familiares. Análisis desde la teoria de la agencia. Caso: Caldas. Criterio Libre. 9 (15), Colombia. (pp. 193-212) https://revistas.unilibre.edu.co/index.php/criteriolibre/article/view/1208/937

Maldonado, Miguel. (2001). Las competencias, una opción de vida. Metodología para el diseño curricular. Ecoe Ediciones. Venezuela

Peña, Dayana. (2014). Análisis de componentes principales en la estimación de índices. Universidad de Granada. España. Extraído de https://masteres.ugr.es/moea/pages/tfm1314/tfmpenamendez/! 
Muratbekova-Touron, Maral. (2009). Why a multinational company introduces a competencybased leadership model: a two-theory approach. The International Journal of Human Resource Management. 20 (3), Reino Unido. (pp. 606-632) DOI: $10.1080 / 09585190802707383$

https://www.researchgate.net/publication/247522511 Why_a multinational company_int roduces a competency-based leadership model A two-theory approach

Pedrosa, Ignacio; Suárez-Alvarez, Javier y García, Eduardo. (2014). Evidencias sobre la Validez de Contenido: Avances Teóricos y Métodos para su Estimación. Acción $\begin{array}{lllll}\text { Psicológica. } & 10 & (2), & \text { España. } & \text { (pp. }\end{array}$ http://scielo.isciii.es/pdf/acp/v10n2/02monografico2.pdf

Perilla, Lyria y Martínez, Maribel. (2009). Evaluación del liderazgo por competencias en los estudiantes de administración de empresas. Revistas Universidad Externado. 13, Colombia. (pp. 46-67) https://revistas.uexternado.edu.co/index.php/sotavento/article/view/1617/1456

Programa de las Naciones Unidas- PUND. (2020). De los ODM a los ODS. Sustainable Development Goals Fund. Extraido de https://www.sdgfund.org/es/de-los-odm-los-ods Rodríguez, Hernando. (2007). El paradigma de las competencias hacia la educación superior. Revista de La Facultad de Ciencias Económicas: Investigación y Reflexión. 15 (1), Colombia. (pp. 145-165). https://revistas.unimilitar.edu.co/index.php/rfce/article/view/4554/3516

Rodríguez, Jorge y Coba, Juan. (2017). Impacto del m-learning en el proceso de aprendizaje: habilidades y conocimiento. Revista Iberoamericana Para La Investigación y EI Desarrollo Educativo (RIDE). 8 (15), México. (pp. 1-24) https://www.ride.org.mx/index.php/RIDE/article/view/303/1439

Sanabria-Rangel, Pedro; Ospin-Díaz, Miltón y García-Carvajal, Santiago. (2019). Competencias profesionales en el campo de administración. Un análisis para Colombia. AD-Minister. 35, Colombia. (pp. 5-52) https://dialnet.unirioja.es/servlet/articulo?codigo $=7212973$

Sanchez, Christian. (18/112019). Analisis de componentes. RPubs. https://www.rpubs.com/Csanchez15/551258

Santa, Laura; Fajardo, Constanza y Macías, Víctor. (2017). Modelo de enseñanza- aprendizaje por capacidades y competencias en la formación de administradores de empresas. Lúmina. $\quad 18, \quad$ Colombia (pp. 110-134) https://revistasum.umanizales.edu.co/ojs/index.php/Lumina/article/view/2716/3181

Santa, Laura; Fajardo, Constanza y Santa, Magda. (2016). Caracterización de las dimensiones de la responsabilidad social empresarial y su relación con las competencias genéricas y específicas en la formación de un profesional efectivo socialmente responsable. Universidad Andina Simón Bolívar, Ecuador. https://www.uasb.edu.ec/UserFiles/385/File/Caracterizacion de las dimensiones de la RSE y su.pdf

Saunders, Mark; Lewis, Philip y Thornhill, Adrian. (2016). Research Methods for Business Students Research Methods for Business Students (Seventh ed). Editorial Harlow; Pearson Education Limited. Germany

Scheaffer, Richard; Mendenhall, William y Ott, Lyman. (2013). Elementos de muestreo. 
Editorial Iberoamérica. Sexta Edición. España

Tacca, Daniel. (2021). Desarrollo de habilidades investigativas desde la experiencia de los estudiantes de Ingeniería. Revista de La Universidad Del Zulia. 32, Venezuela. (pp. 400-413) https://doi.org/10.46925//rdluz.32.24

Tobón, S. (2015). Formación Basada en Competencias. Pensamiento complejo, diseño $\begin{array}{llll}\text { curricular } y \text { didáctica. Ecoe Ediciones. México } & \end{array}$ https://www.uv.mx/psicologia/files/2015/07/Tobon-S.-Formacion-basada-encompetencias.pdf

Universidad de Manizales. (2017). Programa de Administración de Empresas. Acreditación de Alta Calidad: 1042 Del 26 de Enero Del 2015. Extraído de https://umanizales.edu.co/?u_course=administracion-de-empresas

Velasco, Ferran; Batista-Foguet, Joan y Emmerling, Robert. (2019). Are we making progress? Assessing goal-directed behaviors in leadership development programs. Frontiers in Psychology, Vol 10, United States. (pp. 1-15) https://doi.org/10.3389/fpsyg.2019.01345

Winter, Sandra. (2020). SBM Mid-Career Leadership Institute: replacing "fake it till you make it" with authentic leadership. Translational Behavioral Medicine. 10 (4), (pp. 909-911) https://doi.org/10.1093/tbm/ibaa046 https://academic.oup.com/tbm/articleabstract/10/4/909/5919525? redirectedFrom=fulltext

Wong, Gabrielle. (2019). A tool for academic libraries to prioritize leadership competencies. College and Research Libraries. 80 (5), United States. (pp. 597617) https://crl.acrl.org/index.php/crl/article/view/18156/20289

Zapata, Fanny. (12 de febrero de 2021). Homocedasticidad: qué es, importancia y ejemplos. Lifeder. Extraído de https://www.lifeder.com/homocedasticidad/ 